\title{
Heurísticas no Estudo das Decisões Econômicas: Contribuições de Herbert Simon, Daniel Kahneman e Amos Tversky
}

\author{
Adriana Sbicca \\ Professora - Universidade Federal do Paraná (UFPR) \\ Endereço: Av. Prefeito Lothário Meisser, 632 - Curitiba/PR - Brasil \\ CEP: 80210-170 - E-mail: adsbicc@ufpr.br \\ Recebido em 11 de maio de 2013. Aceito em 15 de abril de 2014.
}

\section{Resumo}

Herbert Simon apresenta uma vasta produção acadêmica na qual propôs uma teoria da decisão econômica em torno do conceito de racionalidade limitada. O reconhecimento do meio complexo e dos limites cognitivos levaram-no a sustentar o frequente uso de heurísticas pelo ser humano. Novas abordagens têm sido desenvolvidas ao redor dessa ideia. Mais recentemente, Daniel Kahneman e Amos Tversky analizaram a relação entre heurísticas e vieses de comportamento e esta proposta tem ganhado espaço no mundo acadêmico. Este texto discute as contribuições de Simon, Kahneman e Tversky, e propõe a existência de complementaridade entre as mesmas, promissora para o desenvolvimento de uma teoria da decisão do agente econômico.

\section{Palavras-Chave}

racionalidade limitada, heurísticas, Herbert Simon, Daniel Kahneman, Amos Tversky

\begin{abstract}
Herbert Simon disseminated his bounded rationality approach in his vast academic production. The recognition of the complex environment and the cognitive limits led him to study about the use of heuristics in the decision-making. Around this idea, a new path to the study of human decisions has been developed. More recently, Daniel Kahneman and Amos Tversky have analysed the relation between heuristics and biases of behaviour, and this approach has gained great space in the academic world. This paper discusses the Simon's, Kahneman and Tversky's contributions and proposes a promising complement to the construction of foundations of Behavioural Economy.
\end{abstract}

\section{Keywords}

bounded rationality, heuristics, Herbert Simon, Daniel Kahneman, Amos Tversky

\section{JEL Classification}

B50, D03, D83

\footnotetext{
- A autora agradece aos importantes comentários e sugestões do parecerista anônimo desta revista, isentando-o de qualquer responsabilidade por erros ou omissões remanescentes.
} 


\section{Introdução}

O conceito de heurística, regras que simplificam a tomada de decisão, inspira autores e estimula trabalhos teóricos e experimentos a respeito do comportamento do agente econômico. Um primeiro impulso para estudos ao redor deste tema foi dado por Hebert Simon que, ao final da década de 1940, passou a construir uma abordagem utilizando uma hipótese de racionalidade que enfatizava as limitações cognitivas. Através da incorporação de desenvolvimentos da psicologia, Simon propôs novos fundamentos comportamentais para uma teoria da decisão, alternativos àqueles utilizados na economia até então, que gravitavam em torno da maximização de utilidade. O movimento em direção a essa nova proposta procurava explicar comportamentos que não podiam ser compreendidos através da hipótese de racionalidade substantiva, chamados anomalias, ${ }^{1}$ cuja existência desafiava a teoria tradicional. O conceito de racionalidade limitada levantou um número de questões de natureza filosófica e metodológica e tornou-se um marco para desenvolvimentos teóricos que buscam uma forma alternativa para explicar comportamentos humanos observados.

A partir dos anos 1970, a abordagem denominada "heurísticas e vieses", proposta por Daniel Kahneman e Amos Tversky (doravante $\mathrm{K} \& \mathrm{~T}$ ), teve papel fundamental para conferir um novo impulso ao tema. Esses autores desenvolveram diversos experimentos em que perceberam a existência de efeitos recorrentes nas decisões o que os levou a propor a Teoria dos Prospectos. ${ }^{2}$ De forma alternativa à teoria da decisão mais tradicional, na proposta de K\&T as anomalias são compreendidas como vieses, os quais são explicados por uma estrutura teórica que tem como elemento-chave o uso de heurísticas. O alcance destas ideias foi grande, e sua influência pode ser percebida em diversos campos da ciência com importantes implicações em áreas como regulação, políticas públicas, teoria do consumidor e publicidade.

1 Como destacado nos trabalhos de Allais (1953) e e de Markowitz (1952). (Allais, M. "Le comportement de 1 'homme rationnel devant le risque, critique des postulats et axiomes de lécole americaine". Econometrica, 21, 1953, p. 503-546; Markowitz, H. "The utility of wealth". Journal of Political Economy, 60, 1952, p. 151-158.).

2 Em inglês Prospect Theory, também traduzido como Teoria das Perspectivas. 
O foco comum no uso de heurísticas pelo ser humano gerou um debate a respeito da relação entre os trabalhos de Simon e K\&T. Gerd Gigerenzer, por exemplo, criticou a ênfase nos vieses e sustentou diferenças fundamentais entre essas contribuições procurando mostrar como os trabalhos da abordagem "heurísticas e vieses" não estão de acordo com a hipótese de racionalidade limitada proposta por Simon. ${ }^{3}$ Por outro lado, Arrow (2004) sustentou que os trabalhos de K\&T seguem essa hipótese. Este artigo se insere nesse debate e examina os trabalhos de Simon e K\&T com foco em suas contribuições sobre o papel das heurísticas nas decisões humanas. Ao final, são apresentados aspectos complementares entre as duas abordagens que contribuem para o desenvolvimento de uma teoria da decisão que busca explicar as anomalias apontadas na literatura econômica.

A seção 2 aborda, a partir do conceito de racionalidade limitada, como as heurísticas se inserem nos trabalhos de Simon. Na seção 3 , o trabalho trata do papel central das heurísticas na abordagem de K\&T. Na seção 4, é desenvolvida uma análise da contribuição de Simon e de K\&T, mostrando que as abordagens apresentam características complementares entre si. Por fim, elaboramos uma seção de conclusões, na qual reforçamos a complementaridade e o caráter promissor do desenvolvimento de uma teoria da decisão econômica baseada nos autores analisados.

\section{Heurísticas na Abordagem de Simon}

Herbert Simon teve uma vasta produção acadêmica que pode ser observada como um projeto intelectual em torno de uma nova concepção de racionalidade humana. Em seu artigo "Provérbios de Administração", de 1946, o autor procurou estimular a realização de pesquisas que focassem como as decisões são tomadas de maneira diversa da tradicional maximização de utilidade e de lucros. Ele enfatizou a debilidade da hipótese de que os agentes maximizam para explicar alguns problemas centrais de conflito e de dinâmica com os quais a economia cada vez mais estava preocupada. Segundo Simon (1959, p. 255), a ideia subjacente ao conceito de maximiza-

3 Gigerenzer iniciou um debate com K\&T publicado em Kahneman e Tversky, 1996; Gigerenzer, 1996a e b. 
ção é de um comportamento de equilíbrio de um organismo com perfeita adaptação, que depende apenas de seu objetivo. Mas se o ambiente apresentar alterações, se existirem múltiplos objetivos ou, ainda, se o organismo for afligido por conflitos internos, o conceito de maximização não se mostra promissor. Neste caso, para entender o comportamento do organismo é necessário conhecer sua estrutura interna e, particularmente, seu mecanismo de adaptação.

O caráter inicial da abordagem da racionalidade limitada foi negativo, ou seja, ele procurou mostrar os aspectos da decisão humana que a racionalidade substantiva não incorporava. A ideia ainda geral e vaga de racionalidade limitada foi sendo aprofundada ao longo dos anos 1940, tanto no sentido de formalização da teoria, como no estudo de evidências empíricas (Simon, 1979, p. 501-2). Em Models of Man, Simon (1957, p. 198) afirmou estar em tempo de mudar fundamentalmente sua abordagem de forma a tratar racionalidade limitada não mais como categoria residual, incorporando seus limites empíricos e sua adequação com relação às complexidades do mundo. É nesta publicação que o conceito aparece com todas as suas características (Klaes \& Sent, 2003, p. 13) sendo usado para "designar escolha racional que leva em consideração os limites cognitivos do decisor, limites tanto de conhecimento quanto de capacidade computacional" (Simon, 1987, p. 266). Seu pioneirismo nas pesquisas sobre processo de decisão nas organizações foi um dos motivos mencionados para que Simon fosse agraciado com o Prêmio Nobel de Economia, em 1978.

No conceito de racionalidade limitada proposto por Simon, a característica processual é enfatizada e a forma como as decisões são tomadas é fundamental para se compreender o comportamento humano. Segundo o autor, as pessoas não tentam compreender o mundo como um sistema integral, mas têm modelos parciais tratáveis e identificam padrões recorrentes. As pessoas não levam em conta todas as informações disponíveis necessariamente. Elas tendem a focar aquilo que as preocupa ao invés de enfrentarem informações potencialmente contraditórias e selecionam o que pode ser relevante, reduzindo a sobrecarga de informação.

Fazendo uso recorrente de resultados de estudos empíricos e de dados econômicos que, segundo Simon, não podem ser explicados pela hipótese de racionalidade substantiva, o autor procurou realçar 
as implicações do uso de pressupostos da teoria tradicional para a economia e sua incompatibilidade com o comportamento observado, mostrando a importância de se incorporar elementos da cognição humana. Para o autor, o ambiente econômico complexo e em mudança constante não permite que se admita a priori um equilíbrio de longo prazo na firma. Ele apresentou evidências empíricas para apoiar essa colocação como, por exemplo, de que as regularidades na distribuição das firmas pelos seus tamanhos sugerem relação com o equilíbrio estatístico de uma população de sistemas adaptativos e não o equilíbrio estático de uma população de maximizadores (Simon \& Bonini, 1958).

Tanto nas decisões dos consumidores quanto das firmas, Simon enfatizou a importância das expectativas quanto ao futuro. Consumidores apresentam expectativas quanto à sua renda futura $\mathrm{e}$ estimam o valor de seus planos de gasto para tomar suas decisões de consumo. Os empresários, por sua vez, decidem investimentos e preços de acordo com suas previsões de negócio. Uma explicação possível é que os empresários maximizam o valor esperado dos lucros, mas há dificuldade em mostrar como eles estimam os parâmetros para construir a distribuição de probabilidade conjunta de eventos futuros. Simon (1959, p. 269) sustentou que não há indicação de que o empresário tenha as condições necessárias para agir assim.

Simon argumentou que as decisões humanas buscam satisfação, ideia que permite, e praticamente induz, a incorporação de diversos procedimentos de decisão (Barros, 2010, p. 463). Nestes procedimentos, dois aspectos das decisões humanas foram enfatizados pelo autor e continuaram recebendo atenção especial nos trabalhos posteriores: a busca por alternativas e a referência aos níveis de aspiração. Segundo Simon (1980, p. 503), se as alternativas não são fornecidas inicialmente ao decisor, ele tem de pesquisá-las. Logo, uma teoria de racionalidade limitada deve incluir uma teoria de pesquisa por alternativas. $\mathrm{O}$ agente forma uma aspiração de quão bom deve ser o resultado de sua decisão. Tão logo ele descubra uma alternativa que esteja de acordo com esse nível de aspiração, ele termina a pesquisa e escolhe essa alternativa. Simon chamou este processo de satisficing. 
A ênfase no processo decisório pode ser percebida no emprego do termo racionalidade processual ${ }^{4}$ que passa a ser usado pelo autor com o mesmo significado de racionalidade limitada. ${ }^{5}$

Ao longo de seus trabalhos, Simon manteve a crítica à teoria tradicional baseada na maximização, enfatizando a ausência da ideia de pesquisa, da busca de satisfação e da existência de níveis de aspiração. Ao tratar de racionalidade limitada, Simon usualmente fez três tipos de considerações: quanto à complexidade do ambiente de escolha, quanto ao acesso às informações e quanto aos limites psicológicos do decisor. O ser humano vive num meio que gera milhões de bits de novas informações a cada momento, mas o estrangulamento do aparato de percepção certamente não admite mais que 1000 bits por segundo (Simon, 1959, p. 273). A restrição às informações é uma característica importante para se estudar a escolha do agente, pois a obtenção de informação tem custos, como tempo e esforço do decisor, que podem ter um papel fundamental na determinação da extensão da pesquisa por alternativas de escolha. Quanto aos limites psicológicos, eles são particularmente relacionados à habilidade computacional e preditiva, esta última vinculada à noção de que as informações que o decisor obtém a respeito do ambiente não são uma aproximação e tampouco resultam de um filtro. Essas duas imagens, aproximação e filtro, sugerem que as informações obtidas são próximas do mundo real, o que, para Simon, não é necessariamente uma verdade. Existem informações ausentes, omissões, distorções, ou seja, a apreensão do mundo não é um processo passivo, mas ativo, e o mundo percebido pode ser bastante diferente do mundo real.

Recorrentemente, Simon utilizou como situação de análise o jogo de xadrez, tanto no sentido de se pensar em como programar um computador para jogar, como para entender como mestres enxadristas tomam suas decisões de jogo. Para Simon, o jogo de xadrez é uma espécie de drosófila da inteligência artificial e da pesquisa em ciência cognitiva (Simon \& Schaeffer, 1989, p. 1). Simon enfatizou a impossibilidade dos jogadores pesquisarem totalmente as alternativas de

4 Procedural rationality, nos trabalhos de Simon.

5 Barros (2010) trata da diferença existente entre racionalidade limitada e processual nos trabalhos de Simon. Segundo ele, desde sempre o conceito de racionalidade limitada esteve fundado em procedimentos cujas bases são o satisficing e o processo de busca, mas o conceito tende a ser usado como negação da racionalidade substantiva. Já o uso do conceito de racionalidade processual por Simon, para Barros, enfatiza o aspecto positivo do conceito. Há compatibilidade entre eles, mas não são idênticos. No presente texto, entretanto, os conceitos de racionalidade limitada e processual são usados como sinônimos. 
movimento das peças do xadrez e salientou diversas estratégias que diminuem a necessidade de análise. $\mathrm{O}$ autor observou que a maior qualidade no jogo de mestres enxadristas está relacionada ao uso de estratégias que se baseiam na descoberta de propriedades da posição das peças. A observação dessas propriedades leva à pesquisa de apenas parte da árvore de possibilidades. É uma estratégia bastante poderosa, pois o número de jogadas possíveis, estimado em $10,{ }^{44}$ excede a capacidade de pesquisa plena, seja do ser humano seja da máquina, mesmo no futuro (Simon \& Schaeffer, 1989, p. 1).

Observações como essas levaram Simon a concluir que o ser humano usa atalhos, chamados por ele de heurísticas, para tomar decisões e lidar com a complexidade da vida real, tais como processos de reconhecimento e de determinação da pesquisa por alternativas de escolha (Simon, 1990). Assim como no caso dos enxadristas, ele observou que especialistas fazem uso recorrente do mecanismo de reconhecimento e essa capacidade, que os diferencia dos novatos, está relacionada ao fato de terem mais dicas estocadas e conhecimentos associados. Por utilizar o mecanismo, os especialistas resolvem problemas sem uma análise minuciosa e deliberada das alternativas e esse processo permite que eles retomem informações da memória que os ajudam a tomar as decisões. "A memória humana é organizada como uma enciclopédia muito bem indexada. Dicas de percepção são os itens indexados, os quais dão acesso à informação armazenada a respeito da cena percebida e das ações relevantes", afirmou Simon (1993, p. 642-43).

O mecanismo de determinação da pesquisa é bastante utilizado em problemas cujo número de possibilidades de escolha a ser explorado é muito grande. O ser humano, então, faz uso de alguma regra de seleção que diminui as alternativas a serem analisadas. Um exemplo dessa heurística envolve o uso da experiência para construir uma expectativa de quão boa deve ser a solução para um problema. Quando uma alternativa pesquisada atende a essa expectativa, a pesquisa é encerrada (o que pode significar uma redução no número de alternativas pesquisadas). Além de facilitar a decisão quando o número de alternativas a ser examinado é muito grande, outras várias dificuldades podem ser deixadas de lado com o uso desses métodos, tais como alternativas incomensuráveis ou resultados que afetam muitas pessoas. 
Os indivíduos usam frequentemente heurísticas como as apresentadas para guiar suas ações e alcançar um nível de satisfação (Simon, 1959).

No livro The Science of Artificial, de 1996, ${ }^{6}$ Simon enfatizou a adaptação para se compreender o comportamento humano. Ele propôs a tese de que "certos fenômenos são artificiais num sentido muito específico: eles são assim apenas por serem moldados por metas e propósitos para o ambiente em que vivem. Da mesma forma que os fenômenos naturais têm um ar de 'necessidade' em sua subserviência à lei natural, os fenômenos artificiais têm um ar de 'contingência' na sua maleabilidade em relação ao ambiente.” (Simon, 1996, p. xi). O autor mostrou como o comportamento de um sistema artificial pode ser influenciado por suas características internas, enfatizando os limites de suas capacidades adaptativas - seu conhecimento e poderes computacionais. O problema em torno da artificialidade do sistema é que o meio e o sistema são complexos. Enquanto a visão baseada na racionalidade substantiva supõe que todos os elementos de um sistema artificial estão adaptados ao meio externo, a abordagem baseada na racionalidade processual sustenta que a adaptação é problemática. O comportamento do sistema responde apenas parcialmente à meta já que, internamente, apresenta características que têm de ser levadas em consideração. Necessidades contingenciais surgem exatamente por que o sistema comportamental é incapaz de se adaptar perfeitamente ao ambiente, devido aos limites de sua racionalidade (Simon, 1996, p. xi). Segundo Simon (1996, p. 25), a Economia ilustra bem o processo de ajustamento: a racionalidade do agente apresenta limitações com relação a habilidade, conhecimento e capacidade computacional e a adaptação ocorre, muitas vezes, através de decisões baseadas em heurísticas.

O campo de pesquisa em torno da racionalidade limitada foi se ampliando tanto com sustentações teóricas cada vez mais elaboradas como com evidências empíricas e experimentais mais robustas. A leitura dos trabalhos de Simon assumiu diversas interpretações. Aumann (1997) utiliza o conceito de racionalidade limitada principalmente com relação ao uso de regras de conduta que podem levar, por exemplo, a equilíbrios de Nash. Segundo Sent (1997), esse tipo de incorporação do conceito, feito por Aumann e também por outros

6 A primeira edição deste livro é de 1969, mas em 1996 foi publicada sua terceira edição com acréscimo de mais de cem páginas, motivo pelo qual a utilizamos como base para o presente trabalho. 
pesquisadores da área de teoria dos jogos, ocorre com argumentos mais ortodoxos do que heterodoxos, o que não seria a intenção inicial de Simon. Baumol (2004) critica alguns usos do conceito, por exemplo quando racionalidade limitada é tratada como uma otimização imperfeita, uma forma de camuflar a otimização, envolvendo ponderação para os custos de melhoria de informação e um cálculo mais sofisticado (Baumol, 2004). De fato, segundo Simon (1959, p. 159-60) se a escolha está de algum modo relacionada à racionalidade, então essa racionalidade deve envolver algo mais simples do que a maximização da utilidade do consumidor e dos lucros da empresa. Essa postura do autor tem fundo metodológico. Simon se preocupou em partir de evidências empíricas quanto ao comportamento humano e não de hipóteses que estivessem justificadas pelo poder preditivo da teoria (Archibald, Simon \& Samuelson, 1963). ${ }^{7}$

A otimização com restrições não é a forma mais adequada de representar a racionalidade de Simon e Baumol (2004) apontou três razões para isso: i) o comportamento guiado pelo satisficing pode levar à escolha de uma alternativa bastante diferente daquelas que fazem parte da experiência prévia do decisor, ii) o satisficing pode levar a uma grande redução dos custos de transação em relação àqueles introduzidos na otimização pois tende a diminuir a pesquisa por alternativas e iii) a informação disponível pode ser tão imperfeita que a comparação entre opções, procedimento usual no conceito de otimização, pode explicar pouco do processo decisório.

Essas leituras dos trabalhos de Simon exemplificam um fato relevante: certos autores mencionam as ideias de racionalidade limitada para embasar pesquisas em direções bastante diversas. O próprio Simon se espantou, num simpósio organizado por Prescott, com as explicações baseadas na teoria econômica tradicional para fenômenos que ele acreditava que tinha abordado de maneira satisfatória com relação à estrutura de racionalidade limitada (Sent, 2005, p. 228). Neste mesmo sentido, Sargent, em sua publicação Bounded Rationality in Macroeconomics, de 1993, procurou aproximar expectativas racionais das ideias de Simon (Sent, 1997). Sobre isto Simon contrapôs que

\footnotetext{
A ênfase na característica metodológica da abordagem pode ter reflexos na análise. Silveira (1991, 1994) chama a atenção para a existência de teorias econômicas mais abstratas e teorias com preocupações mais empíricas. Segundo este autor, Simon trabalha numa dimensão de análise que procura desenvolver uma teoria mais aplicada. Já autores como Milton Friedman contribuem no âmbito da teoria abstrata ao utilizar argumentos ficcionistas. Para Silveira, essa diferença impossibilita uma comparação direta entre os trabalhos de Simon e contribuições como as de Friedman.
} 
na '... abordagem adaptativa das 'expectativas racionais', as possibilidades de que um sistema de processamento de informação possa ter uma capacidade limitada de adaptação são quase ignoradas" (Simon, 1996, p. 24).

Segundo Simon, compreender a racionalidade limitada como um processo de maximização sob restrições esconde a substância do tema. Ao utilizar a hipótese da otimização, é necessário tratar somente das metas do decisor, pois o resultado depende apenas delas. Já na busca por satisfação, além das metas é necessário analisar também o ambiente em que a decisão é tomada, bem como a estrutura interna do organismo, uma vez que esses dois fatores podem influenciar os mecanismos de adaptação e a decisão. O processo decisório é fundamental para a abordagem da satisfação proposta por Simon, e é desnecessário numa abordagem de maximização. Simon (1980) usou como analogia o comportamento de melado escorrendo dentro de um recipiente. Segundo ele, a visão tradicional analisaria apenas o estado de equilíbrio alcançado ao término desse processo, enquanto que uma abordagem a partir da racionalidade limitada tem de levar em consideração também as forças que agem sobre o melado, tanto aquelas que o fazem escorrer, como aquelas que vão gerar o resultado final caso o ambiente se estabilize. A maneira como essas forças agem sobre o melado depende de características internas como viscosidade e rapidez com que o melado se adapta ao novo recipiente e se move no sentido de abaixar o centro de gravidade (Simon, 1980). Assim, tratar de racionalidade limitada envolve características internas do agente, forças do meio e adaptação.

\section{A Abordagem Heuristics and Biases}

Os psicólogos Amos Tversky e Daniel Kahneman iniciaram uma frutífera colaboração a partir de 1969. Em 1974, publicaram um artigo na revista Science intitulado Judgment under Uncertainty: heuristics and biases e, em 1982, um livro com este mesmo título. Estes trabalhos se tornaram marcos da abordagem que os autores denominaram heuristics and biases. O foco destas publicações estava nos princípios heurísticos que criam atalhos para julgamentos de probabilidade. Argumentavam os autores que muitas decisões são baseadas em crenças construídas a respeito de fatos e/ou processos que não são 
conhecidos com certeza. Diante de situações como essas, as pessoas fazem uso de regras simples que reduzem a complexidade das decisões. Para eles, "Em geral, estas heurísticas são totalmente úteis, mas algumas vezes elas levam a erros graves e sistemáticos." (T\&K, 1974, p. 1124). A percepção da ocorrência sistemática de comportamentos que se afastam daqueles esperados pela teoria tradicional de racionalidade - as anomalias - é a inspiração das pesquisas dos autores. Para K\&T, recorrentemente, os decisores utilizam regras simples que acabam resultando em vieses. As pessoas fazem uso dessas regras porque normalmente não analisam os eventos em listas exaustivas para agregá-los, e nem mesmo avaliam suas probabilidades de ocorrência. Os autores desenvolveram o estudo dessas heurísticas de modo a encontrar elementos que ajudassem a compreender as decisões humanas, e essa abordagem ganhou paulatinamente importância na pesquisa econômica.

Kahneman e Tversky buscaram fundamentação empírica através de diversos experimentos nos quais é verificada a existência dos vieses de comportamento. $\mathrm{O}$ método utilizado pelos autores envolveu a observação e análise de características recorrentes nas decisões e a especificação de atributos que as influenciam e as afastam daqueles resultados que seriam obtidos de acordo com a Teoria da Utilidade Esperada.

Muitos dos experimentos utilizados envolviam conhecimento de estatística, como a proposta de estudo de loterias que, nos trabalhos de Kahneman, como ele mesmo afirmou, seria o equivalente ao estudo da mosca da fruta, um dos mais importantes organismos-modelo da biologia. Nessas loterias os indivíduos fazem escolhas entre duas alternativas sobre as quais são informados com relação ao prêmio e à probabilidade de ganhar e de perder. As opções são representadas por $\mathrm{L}=(\mathrm{x} ; \mathrm{p})$, onde $\mathrm{x}$ é o valor do prêmio e $\mathrm{p}$ é a probabilidade de ganhar. Assim, $\mathrm{Ll}=(4.000 ; 0,20)$ representa a alternativa de ganhar 4.000 com probabilidade de $20 \%$ e também representa a probabilidade complementar de $80 \%$ de nada ganhar. ${ }^{8}$ K\&T chamaram

8 Num experimento deste tipo, 95 indivíduos escolhiam primeiro entre $\mathrm{Ll}=(4.000 ; 0,20)$ ou L2 $=(3000 ; 0,25)$. Em outro momento as mesmas pessoas escolhiam entre L3 = $(4.000$; $0,80)$ ou L4 $=(3.000 ; 1)$. Ganha-se zero com probabilidade (1-p). Kahneman e Tverky (1979, p. 266) relataram que $65 \%$ das pessoas escolheram a alternativa $\mathrm{Ll}$ na primeira loteria mas, na segunda situação, $80 \%$ optaram pela L4. Os autores chamaram a atenção para o fato de que estes resultados não estão de acordo com as características da Teoria da Utilidade Esperada tradicional. De acordo com ela, as pessoas escolhem a melhor alternativa ponderada pela sua respectiva probabilidade, ou seja, no teste, a decisão da maioria das pessoas não 
a atenção para o fato de que muitas das escolhas observadas não estavam de acordo com as características da Teoria da Utilidade Esperada tradicional. Os autores constataram algumas tendências comportamentais que diferiam de escolher a melhor alternativa, ou seja, o maior valor obtido após o cálculo do prêmio ponderado pela respectiva probabilidade. Segundo K\&T, há uma tendência das pessoas de superestimarem resultados que são considerados certos por que apresentam alta probabilidade de ocorrer em relação a resultados considerados prováveis (com mais baixa probabilidade de ocorrência). Como consequência deste efeito, alternativas com probabilidade próxima a 1 se tornam muito mais atraentes, e a ponderação entre prêmio e probabilidade não é usada para guiar a escolha. Esta maior atração pelos resultados mais próximos do certo foi denominada de efeito certeza, um conceito importante no arcabouço teórico proposto mais tarde por Kahneman e Tversky.

Outro teste ilustra a estrutura dos estudos feitos pelos dois autores. Foram dados sessenta segundos a estudantes da University British Columbia para construir duas listas com palavras em inglês com sete letras sendo que, na primeira lista, a sexta letra deveria ser " $n$ " e, na segunda, as palavras deveriam terminar em "ing". Como resultado, eles listaram muito mais palavras terminando com "ing" do que com "_n_" (médias de 6,4 e 2,9, respectivamente) (T̄\&K, 1983 , p. 295). Os autores chamaram a atenção para o fato de que a última forma (_n_) inclui a primeira (_ing); palavras como writing, working, filling e biasing poderiam estar nas duas listas, mas outras como airline, account e reprint, só poderiam constar da segunda lista. Seria esperado, portanto, que a lista contendo a forma "_n_" fosse maior, ou, no mínimo, igual à primeira, o que se contrapõe ao resultado obtido no experimento. K\&T explicaram esse resultado argumentando que as palavras terminadas com "ing" estão mais disponíveis em nossa memória. Segundo Kahneman, esse é um exemplo de uso de heurística da disponibilidade (availability heuristics), que se refere à maior influência, nas decisões, de eventos que são mais fáceis de imaginar ou de se lembrar. O uso desta heurística pode

correspondeu à maximização da utilidade esperada, pois L1 e L3 deveriam ser preferidos e não Ll e L4, como ocorreu. Ainda, os resultados obtidos não respeitaram o axioma de independência de von Neumann \& Morgenstern, que sustenta que a presença de um evento diferente não influencia a escolha entre dois eventos que estão sendo avaliados pelo decisor. Para verificar isso basta notar que as probabilidades das loterias 3 e 4 são iguais às das loterias 1 e 2 multiplicadas por 4 . Assim, $0,80=0,20 * 4$ e $1=0,25 * 4$. O axioma da independência requer que a escolha de L1 seja acompanhada da escolha de L3 e não L4 como ocorreu no teste pois a multiplicação por 4 não pode alterar a escolha. 
explicar o fato de as pessoas tenderem a superestimar a probabilidade de eventos que ocorreram recentemente em relação àqueles que aconteceram há mais tempo (como o medo de viajar de avião devido à ocorrência de um acidente recente ou o aumento da procura por seguro logo após um terremoto). ${ }^{9}$

$\mathrm{K} \& \mathrm{~T}$ analisaram os julgamentos nos experimentos, ressaltando que recorrentemente ocorrem vieses com relação à resposta que seria esperada, mesmo por parte de pessoas que têm conhecimento para tomar a decisão. Isso acontece inclusive em julgamentos feitos por experts em princípios estatísticos (T\&K, 1971) ou com estudantes da Universidade de Estocolmo e de Michigan (K\&T, 1979). Assim, não é o desconhecimento das regras estatísticas ou das leis da probabilidade que impede seu uso nas inferências intuitivas. Os experimentos com pessoas que têm esse conhecimento garantiriam, segundo os autores, a clara identificação do que é mais correto, sem depender das diferenças de informações dos participantes e de suas crenças. Não garante, porém, que as regras estatísticas serão aplicadas corretamente na solução dos problemas.

Uma regra identificada por K\&T e amplamente usada na ciência desde então é a heurística da ancoragem. Ao utilizá-la, o decisor adota um valor como referência, ou âncora, para um julgamento posterior, mesmo que ela não seja objetivamente relevante para a decisão. $\mathrm{O}$ uso da regra da ancoragem faz com que a decisão seja influenciada, por exemplo, pela ordem em que os dados são apresentados ao decisor, que pode usar os iniciais como parâmetro para ajustar as informações posteriores (por isso esta heurística é frequentemente chamada de "ancoragem e ajustamento") (T\&K, 1984).

Estes exemplos se tornaram clássicos na literatura sobre heurísticas e ilustram a maneira como os autores desenvolveram seu programa de pesquisa: estudaram vários tipos de decisão, observaram os vieses e procuraram suas causas nas heurísticas utilizadas. Tversky e Kahneman (1974, p. 1124) afirmaram que "as pessoas se baseiam em um número limitado de princípios heurísticos que reduzem as tarefas complexas de avaliar probabilidades e predizer valores para operações de julgamento mais simples".

9 Esse tema é trabalhado, por exemplo, em HSEE, C.K. \& Kunreuther, H. C. (2000) "The affestion effect in insurance decisions" Journal of Risk and Uncertainty, 20:2, 141-159. 
A partir das observações dos experimentos, os autores procuraram conceituar tipos de efeitos que influenciam as decisões e especificar diversas heurísticas utilizadas pelo ser humano - elementos que subsidiaram sua crítica ao papel descritivo da Teoria da Utilidade Esperada. Suas pesquisas foram formando um arcabouço teórico e, em 1979, K\&T escreveram Prospect Theory: an analysis of decision under risk, um dos artigos mais citados da revista Econometrica (Camerer \& Loewenstein, 2002, p. 5).

$\mathrm{Na}$ Teoria dos Prospectos o efeito certeza contribui para a aversão ao risco em escolhas que envolvem ganhos e para uma propensão ao risco em decisões que envolvem perdas. Há um comportamento diferenciado quanto às perspectivas positiva (envolvendo ganhos) e negativa (envolvendo perdas) que K\&T (1979) denominaram de efeito reflexão. No primeiro caso, a aversão ao risco é observada e é acentuada pelo efeito certeza já que há um aumento da atração por resultados considerados certos. Quando perdas estão em jogo, há um comportamento de apreciação de riscos, ou seja, uma preferência por risco com perdas maiores que são meramente prováveis em face de uma perda menor que é vista como certa por apresentar maior probabilidade. Esse efeito é a base da curva de utilidade em forma de S proposta por K\&T (Gráfico 1 abaixo). Nesta curva destaca-se: i) a manutenção, como na teoria tradicional, de uma função valor, mas agora definida sobre ganhos e perdas e não sobre riqueza total; ii) a concavidade no domínio dos ganhos e convexidade no das perdas e iii) a maior inclinação das perdas em relação aos ganhos; a expectativa de perder $\$ \mathrm{X}$ produz maior aversão do que a atração provocada pela possibilidade de ganhar \$X (K\&T, 2000, p. 3).

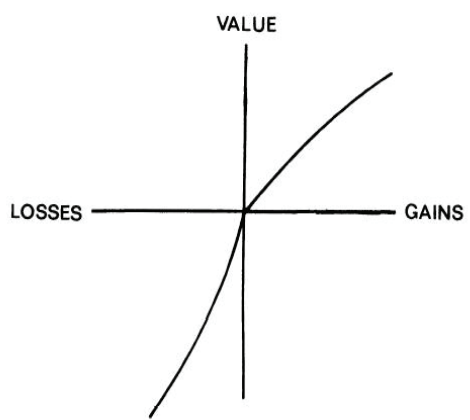

Gráfico 1- Curva em S da Teoria dos Prospectos

Fonte: K\&T, 1979, p. 279.

Estud. Econ., São Paulo, vol.44, n.3, p.579-603, jul.-set. 2014 
As implicações dessa curva ferem os axiomas de von Neumann e Morgenstern, pois não respeitam os axiomas da transitividade e substitutibilidade (K\&T, 2000, p. 4).

Segundo Kahneman (2003, p. 1469), as teorias em economia comportamental muitas vezes mantêm a arquitetura padrão da teoria da decisão tradicional, e apenas adicionam hipóteses de limitações cognitivas em determinadas situações de decisão. Sua proposta com Tversky, continuou Kahneman, não mantém essa arquitetura, pois, devido à forte dependência do contexto, não se pode dizer que o agente usa a razão de maneira pobre, mas sim que ele age muitas vezes intuitivamente. Também não se pode dizer que os comportamentos dos agentes são guiados pelo que ele é capaz de computar, mas sim devido ao que os agentes percebem no momento da decisão.

Kahneman (2002a, p. 456) salientou que a invariância é outro aspecto essencial da visão tradicional da racionalidade que é violada em demonstrações do efeito framing. Esse efeito surge quando descrições de um problema ressaltam aspectos distintos dos resultados possíveis, ocasionando respostas diferentes para o que é, na verdade, o mesmo problema. De outra forma, isso significa que a maneira como as escolhas são apresentadas a um indivíduo muitas vezes influencia as preferências que são "reveladas". Para exemplificar, a descrição pode determinar se os resultados são vistos como ganhos ou perdas e, consequentemente, se promovem aversão a risco ou apreciação a risco. Há maior aceitação pelo paciente em se submeter a um tratamento médico de alto custo ou que causa alguma dor se lhe for dito que existe $20 \%$ de chance de obter a cura do que se for afirmado que o tratamento tem $80 \%$ de chance de insucesso. (T\&K, 2000, p. 217-218).

K\&T utilizaram os conceitos de Sistemas 1 e 2 ao se referirem à distinção entre dois processos cognitivos: a intuição e a razão. A intuição está relacionada a operações rápidas, automáticas, sem esforço, associativas e que se tem dificuldade de modificar ou controlar, denominada "Sistema l". A razão é mais lenta, serial, requer esforço e é deliberadamente controlada, chamada de "Sistema 2". A partir de suas observações empíricas, os autores sustentaram que o Sistema 2 monitora as decisões, mas isso não ocorre plenamente, e muitas decisões apresentam grande participação da intuição: são processos intuitivos e não deliberativos. Há alguns atributos que 
são registrados de maneira rotineira e automática, sem intenção ou esforço pelo Sistema 1: tamanho, distância, sonoridade, propensão causal, surpresa e disposição de ânimo (Kahneman, 2002a, p. 4504). O decisor pode não se dar conta de que tais atributos influenciam suas decisões e esta pode ser a causa de vieses. $\mathrm{O}$ teste envolvendo palavras com "_n_" e "_ing" ilustra a maior acessibilidade de determinados atributos e sua influência na decisão.

Representatividade, disponibilidade e framing são conceitos que, introduzidos numa teoria da decisão, possibilitaram explicações para muitos comportamentos observados, o que os tornou bastante utilizados por autores que trabalham com teoria comportamental e também por aqueles que procuram analisar padrões de decisão em ambientes específicos, como decisões jurídicas, médicas e de consumo. ${ }^{10}$ A proposta de K\&T teve um papel importante no crescente interesse pela economia comportamental, evidenciado pelo reconhecimento conquistado por Kahneman ${ }^{11}$ ao ser agraciado com o Prêmio Nobel de Economia de 2002, que ele dividiu com Vernon Smith.

\section{A Complementaridade entre as Propostas de Simon, Kahneman \& Tversky}

O fato de as publicações de Simon serem anteriores às de Kahneman e Tversky pode gerar a indagação quanto à influência recebida por K\&T. Não há indicação de que eles tenham se inspirado em Simon, que tenham procurado trabalhar a partir do conceito de racionalidade limitada, e não há menção a Simon nos seus trabalhos da década de 1970.

${ }^{10}$ Podem ser citados alguns trabalhos para ilustrar a abrangência da utilização da abordagem de K\&T. Exemplo de texto que tratou de decisões de consumo é Kivetz, Ran; Simonson, Itamar (2000) "The effects of incomplete information on consumer choice" Journal of Marketing Research, 37 (4), nov., p. 427-448. Quanto a decisões na área médica: Redelmeier, Donald A.; Tibshirani, Robert J., (1997) "Association between Cellular-Telephone Calls and Motor Vehicle Collisions" The New England Journal of Medicine, fev. 13, p. 336:453-458 e o livro de Jerome Groopman de 2007 intitulado How Doctors Think. De Mark Kelman da Stanford Law School temos um exemplo da influência de Kahneman na análise de decisões da área jurídica: "Hedonic Psychology, Political Theory and Law (I): Is Welfarism Possible? " Working Paper 242, Set. 2002. Também pode ser citado o texto de Christine Jolls e Cass Sunstein, de janeiro de 2006, "Debiasing through Law" publicado no, Journal of Legal Studies, vol. 35, p. 199-241.

${ }^{11}$ Amos Tversky faleceu em 1996, o que o tornou inelegível ao prêmio, mas Kahneman reconheceu que foi o trabalho em conjunto que ganhou o Nobel. 
Deixada a questão de lado, podemos pensar a respeito das contribuições dos autores para o desenvolvimento de uma teoria da economia comportamental. O esforço interdisciplinar de incorporação da psicologia à análise da decisão econômica e a importância dada às evidências empíricas são características marcantes nos trabalhos de Simon, Kahneman e Tversky. Seus textos apresentam uma das características apontadas para a Economia Comportamental em geral: a procura por hipóteses com maior congruência com a realidade, as quais, ao serem incorporadas à teoria, tornam possível explicar algumas anomalias percebidas.

O agente descrito por Simon realiza uma apreensão subjetiva da realidade e faz inferências quanto ao futuro para tomar decisões, características também apontadas por K\&T, evidenciadas nos efeitos ancoragem e framing e na avaliação das alternativas de escolha (Kahneman, 2002a, p. 463).

A importância das heurísticas é evidente tanto na abordagem em torno da racionalidade limitada como na "heurísticas e vieses". Mas a maneira como os autores trabalharam é diferente. Simon sustentou o uso recorrentente de heurísticas e o fez detalhando as etapas usadas pelo ser humano para tomar decisão, o que é enfatizado pelo uso que faz de protocolos verbais através dos quais o indivíduo revela informações que dão conta do que ele vai pensando passo a passo durante seu processo decisório. Em seus experimentos, K\&T observaram os comportamentos chamados de vieses e os explicaram através das heurísticas supostamente utilizadas pelo decisor, sendo as mais comuns a heurística da representatividade (julgamentos influenciados pelo que é mais típico), da disponibilidade (julgamentos baseados no que vem mais facilmente à mente) e da ancoragem (julgamentos que se baseiam em determinadas informações usadas como referência) (T\&K, 1983).

É interessante notar que, apesar das maneiras diferentes de trabalhar, algumas análises dos três autores se assemelham. Um exemplo é a explicação para os resultados esperados pelas pessoas com o tradicional "cara ou coroa". Simon e K\&T perceberam que, em qualquer sequência de eventos de uma moeda sem vício, as pessoas esperam observar um resultado próximo a 50\% para cada alternativa. Simon (1959, p. 257) chamou situações como essa de "falácia do jogador", e enfatizou que esse é um exemplo de que probabilidade objetiva deve 
ser diferenciada de probabilidade subjetiva. Já K\&T salientaram que esse comportamento pode ser observado mesmo numa sequência de amostras pequenas, o que os levou a chamar essa tendência de "lei dos pequenos números" (T\&K, 1971), cuja causa estaria no uso da heurística de representatividade: as pessoas tendem a acreditar que amostras são muito semelhantes à população da qual foram tiradas, e apresentam as mesmas características mesmo que as amostras sejam pequenas.

A observação de suas "drosófilas", o xadrez para Simon e as loterias para K\&T, levou os autores a conclusões muito semelhantes também quanto à diferença entre o novato e o expert. Simon notou que as posições do jogo são como dicas para o enxadrista. Quando as peças são dispostas aleatoriamente em um tabuleiro de xadrez, sem representarem um jogo em andamento, os experts não reconhecem posições e apresentam o mesmo desempenho de novatos na memorização das posições das peças. Isto ocorre porque os experts não reconhecem as "dicas" que são as posições que recorrentemente encontram ao jogar (Simon \& Schaeffer, 1989, p. 4). De maneira semelhante, para Kahneman (2002a, p. 483) a diferença entre expert e novato depende do contexto da decisão. Se esse contexto não fornece dicas para que o conhecimento seja acessado, não há diferença entre as duas classes de pessoas. Como Simon, Kahneman (2002b) afirmou que a destreza do bom enxadrista se encontra no fato de conseguir reconhecer padrões de jogada e usá-los para escolher sua estratégia no jogo.

Os trabalhos de Simon propõem alicerces para a construção de uma nova abordagem na qual não há a utilização de uma estrutura teórica já estabelecida pela abordagem tradicional. Em seus trabalhos, a definição de racionalidade, de decisão e o critério de bom resultado são "inovadores". A racionalidade é limitada, mas não no sentido apenas de impor restrições à racionalidade maximizadora. A compreensão da decisão não envolve apenas o seu resultado, mas também a análise do processo decisório e o bom resultado deve levar em consideração o ambiente da escolha, restrições de tempo e esforço, os objetivos e o nível de aspiração do decisor. K\&T não construíram nem assumiram um conceito de racionalidade e tampouco tiveram essa preocupação. Por vezes disseram que seus trabalhos estão de acordo com a racionalidade limitada desenvolvida por Simon (T\&K, 1986, p. S273; Kahneman, 2000, p. 774). 
K\&T avaliaram os resultados alcançados nas decisões utilizando como referência as leis lógicas e estatísticas que seriam usadas pelo agente racional maximizador. Por um lado, essa retórica pode ter sido mais eficiente em mostrar a debilidade da teoria tradicional. Por outro lado, é um dos motivos de críticas, por exemplo de Gigerenzer (1996b) e Altman (2011), que sustentaram que K\&T trataram de irracionalidade, apesar de Kahneman (2002b) não concordar. A leitura dos trabalhos de Simon e K\&T mostra que a proposta teórica de Simon procurou envolver âmbitos mais amplos do que a Teoria dos Prospectos. Conflitos internos e interpessoais e, ainda, formação de aspiração e aprendizagem estão presentes e são discutidos em torno de um conceito de racionalidade limitada. K\&T tiveram um foco mais específico: insights a partir de decisões individuais observadas em experimentos que levam a vieses. Neste sentido, pensando a respeito do motivo da racionalidade limitada ser menos aceita que a chamada Behavioral Economics centrada nos vieses, Rubinstein (2006, p. 246) concluiu que os economistas preferem progressos em pequenos passos: os modelos da Behavioral Economics não são tão diferentes daqueles da economia aplicada e, por isso, não são percebidos como ameaça.

Simon e K\&T propuseram teorias da decisão em que heurísticas têm um papel fundamental. As situações observadas por Simon, menos controladas que aquelas trabalhadas por K\&T através de experimentos, apontaram para a conveniência da incorporação de outras características, como a existência de diversos papéis sociais e objetivos, que podem entrar em conflito tornando mais complexa a decisão. Essas características, juntamente com a complexidade do ambiente no qual o processo decisório ocorre, formam uma base teórica para a sustentação da necessidade do uso de heurísticas nos trabalhos de Simon. A aparente ausência nos trabalhos de K\&T de desenvolvimentos nos quais o ambiente complexo é variável fundamental está relacionada a essa diferença no ambiente decisório que eles analisam. Simon observou eventos e procurou compreender como a decisão é tomada, muitas vezes usando informações fornecidas pelo decisor. Já K\&T propuseram experimentos de laboratório nos quais procuraram controlar o meio externo (quanto às restrições de tempo para decisão, sugerindo a situação inicial ao decisor e mudanças ao longo das questões propostas, etc.) e também as características internas, na medida em que escolheram o grupo para aplicar o teste (quanto ao nível de conhecimento de estatística, por exemplo). 
Procurando contornar outros elementos envolvidos na decisão, como o desejo de acerto, muitas vezes K\&T informaram aos participantes a inexistência de resposta errada, objetivando não criar restrições ao uso da intuição. A diferença entre os ambientes de decisão que K\&T e Simon analisaram não significa incompatibilidade entre as duas propostas e podemos pensar nas contribuições que os dois modos de trabalho apresentaram e na sua complementaridade.

Utilizando o chamado processo dual apresentado por K\&T, os Sistemas 1, intuitivo e 2, deliberativo, percebemos importantes características dos trabalhos de Simon e da abordagem heurísticas e vieses. Talvez fruto da frequente observação de enxadristas, nos trabalhos de Simon o decisor escolhe qual heurística usar e isso faz com que a decisão envolva muita deliberação, o que requer maior esforço cognitivo (Muramatsu, 2006, p. 64-65). Entretanto, talvez nem sempre tanta deliberação esteja envolvida nas decisões e a falta de uma análise mais atenta sobre os temas da intencionalidade e da causalidade por parte de Simon foi percebida como uma possível fonte de objeção a seu trabalho, pois seus estudos não acomodam inferências e escolhas feitas de maneira automática e não deliberada (Muramatsu, 2006, p. 65). Exatamente esse tipo de escolha, ausente nos trabalhos de Simon, foi objeto dos trabalhos de K\&T que buscaram compreender como decisões ocorrem muitas vezes de maneira intuitiva, sem (ou com débil) monitoramento do resultado obtido. Sob o ponto de vista de processo cognitivo dual com o Sistema 1, intuitivo, e Sistema 2, mais deliberativo, a leitura dos trabalhos em torno de racionalidade limitada e de vieses aponta diferentes enfoques quanto à deliberação da decisão e revela que as decisões estudadas por Simon são complementares às analisadas por K\&T. Simon observa decisões mais deliberadas, com preponderância do Sistema 2 , enquanto a abordagem "heurísticas e vieses" se debruça sobre decisões mais intuitivas, características do Sistema 1. As duas contribuições são propostas de explicação com a utilização da psicologia cognitiva envolvida nas decisões tomadas automaticamente (K\&T) e nas decisões mais deliberadas (Simon).

Simon, Kahneman e Tversky são reconhecidos como importantes autores da Behavioral Economics. Algumas citações de Simon que fizeram K\&T, e vice-versa, mostram o reconhecimento mútuo da relevância de suas constribuições. Quattroni \& Tversky (1988, p. 452) apontaram Simon como tendo influenciado a incorporação da psico- 
logia cognitiva na economia. Também os próprios K\&T sustentaram que os resultados e análises que eles desenvolveram são consistentes com a concepção de racionalidade limitada de Simon (T\&K, 1986, p. 220; Kahneman, 2000, p. 774). Simon, por sua vez, citou K\&T em seu discurso do Prêmio Nobel por terem apresentado de maneira mais enfática e convincente refutações à Teoria da Utilidade Esperada (afirmação presente também em Simon, 1985, p. 296).

O foco de K\&T, menos amplo e mais específico em relação ao de Simon, gerou uma proposta de estudo de como as heurísticas se relacionam a diversas situações cotidianas da vida econômica, em análises de várias situações usuais como contratação de seguros, ${ }^{12}$ decisões no mercado financeiro, ${ }^{13}$ uso do cartão de crédito ${ }^{14}$ etc. $\mathrm{K} \& \mathrm{~T}$ procuraram descrever sistematicamente como as heurísticas produzem padrões de comportamento observáveis e encontraram efeitos que muitas vezes reforçaram aspectos já tratados por Simon, como a influência do ambiente sobre a decisão e as restrições cognitivas enfrentadas pelo decisor.

Segundo K\&T, há ocorrência de vieses de comportamento que não decorrem da falta de disponibilidade de informação, ou seja, da situação de informação imperfeita. As pessoas fazem uma leitura pessoal do problema proposto, da situação em que a decisão se encontra, e elas têm um conhecimento prévio que muitas vezes é usado na decisão, salientaram K\&T, de maneira semelhante a Simon. A ênfase nesses elementos envolvidos no processo decisório já havia sido dada por Simon quando chamou atenção para a representação que o ser humano faz do mundo, na qual inclui aquilo que acredita ser mais importante. É a partir de K\&T que essas características cognitivas são incorporadas mais fortemente na economia e muitos autores reconhecem a ideia dos vieses como um tema central dos modelos da Behavioral Economics. Para Rubinstein (2006, p. 247) é quase impossível publicar um texto na QJE que ignore vieses. Com essa predominância da relação entre heurística e viés, ganha impor-

12 Um exemplo é o artigo de P. P. Wakker, Richard Thaler \& Amos Tversky de 1997, "Probabilistic Insurance" publicado no Journal of Risk and Uncertainty. Ou ainda Johnson, E., Hershey, J. Meszaros, J. \& Kunreuther, H. (1995) "Framing, Probability Distortions and Insurance Decisions," Journal of Risk and Uncertainty 7, p. 35-51.

${ }^{13}$ Veja, por exemplo, De Bondt, Werner F. M. \& Thaler, Richard H. (1995) "Financial decision making in markets and firms: a behavioral perspective" in Hadbook of Finance, Jarrow, R. A. \& Ziemba, W. T. (eds.), Amsterdam: Elsevier-North Holland.

${ }^{14}$ Por exemplo em Stewart, N. (2009) "The cost of anchoring on credit-card minimum repayments", Psychological Science, v. 20, n. 1, jan., p. 39-41. 
tância a contribuição de Simon, sua análise de decisões com maior deliberação e a visão positiva que ele tem de heurística para que não se perca essa dimensão do estudo das decisões do agente econômico.

\section{Conclusões}

Os trabalhos de Simon e de K\&T trataram de decisões nas quais a apreensão da realidade é um processo ativo de edição e no qual o ser humano se utiliza de mecanismos para facilitar o processo decisório: as heurísticas. As diferenças entre suas abordagens revelam contribuições complementares bastante frutíferas para a construção de uma teoria da decisão do agente econômico.

Simon ressaltou os bons resultados alcançados com o uso de heurísticas tornando possíveis decisões que, se fossem tomadas utilizando todas as informações disponíveis, não seriam viáveis. A abordagem "heurísticas e vieses", por sua vez, enfatizou os vieses que ocorrem devido ao uso de heurísticas em relação ao resultado que teria sido atingido se o agente fosse 100\% racional (como conceituado pela teoria econômica tradicional). São duas ênfases com relação a heurísticas que revelam uma complementaridade promissora. Essas visões se complementam na medida em que as evidências empíricas mostram que as heurísticas podem gerar bons e maus resultados.

Ao analisar as duas abordagens, restrições para a decisão (como tempo, recursos econômicos e cognitivos) e o contexto se tornam importantes para se pensar sobre o uso de uma heurística. No primeiro caso, o uso de regras de conduta pode tornar uma decisão possível ou a aspiração do indivíduo pode ser tal que o resultado obtido o satisfaça, apesar de existirem resultados melhores. No segundo caso, decisões podem parecer contraditórias quando isoladas de seu meio, mas podem ser analisadas de forma diferente quando contextualizadas, o que as abordagens propõem.

Simon propôs novos alicerces para uma teoria da decisão com um conceito de racionalidade novo. Seu conceito de satisficing impõe um desafio que nos parece intransponível para a incorporação de seu conceito de racionalidade pela teoria tradicional, porque elimina a ideia de maximização e introduz um conceito subjetivo e impreciso 
de escolha. Mesmo que sem pretensão tão revolucionária como a do trabalho de Simon, K\&T se preocuparam em analisar situações incompatíveis com a proposta tradicional e elaboraram insights a partir delas. Pode ser analisado como uma posição mais reformista que a de Simon, mas nem um pouco conservadora na medida em que os axiomas principais da teoria tradicional (transitividade, substitubilidade e independência) não se mantêm intactos. Sob a perspectiva apresentada neste texto, o trabalho de K\&T auxilia na aproximação das hipóteses ao mundo real buscada por Simon (Archibald, Simon, Samuelson, 1963, p. 230), seja pela documentação dos vieses, pelos efeitos encontrados que influenciam as decisões, ou pela identificação das heurísticas utilizadas. Mais do que isso, K\&T procuraram mostrar como se relaciona o uso de heurísticas a causas de comportamentos no mundo real em situações comumente tratadas pela teoria econômica.

Como nos trabalhos de Simon, o conceito de racionalidade sustentado por K\&T não se adequa ao agente racional tradicional. Assim, a arquitetura de uma teoria que possa explicar os vieses apresentados por K\&T, no mínimo, desafia a teoria da decisão mais tradicional. A tentativa de enfrentar essa nova demanda através de pequenas adições à teoria tradicional não está impossibilitada. A História do Pensamento Econômico nos mostra que os programas de pesquisa apresentam uma dinâmica bastante imprevisível. Teorias que pareciam perder força, em momentos posteriores ganham espaço, e viceversa, devido a modificações de suas características. Como ocorrerá a incorporação dos insights de K\&T a uma teoria da decisão não está definido, mas um caminho possível e promissor é o aprofundamento da complementaridade com as ideias de Simon. 


\section{Referências}

ALTMAN, M. Behavioural Economics Perspectives: implications for policy and financial literacy, SSRN Working Paper. 2011. Disponível em: http://papers.ssrn.com/sol3/papers.cfm?abstract_ id=2013449. Acesso em: 02 de maio de 2013.

ARCHIBALD, G. C.; SIMON, H. A.; SAMUELSON, P. A. "Discussion”. American Economic Review, Papers and proceedings of the seventy-fifth annual meeting of de AER, 53 (2), p. 227-236, 1963.

ARROW, K. J. “Is Bounded Rationality Unboundedly Rational? Some Ruminations”. In: Augier, M.; March, J. Models of a Man-essays in memory of Herbert A. Simon. MIT Press, Cambridge (MA) \& London, p. 47-56, 2004.

AUMANN, R. J. "Rationality and bouded rationality” Games and Economic Behavior 21, p. 2-14, 1997.

BARROS, G. "Herbert A. Simon and the concept of rationality: boundaries and procedures" Revista de Economia Política, 30 (3), p. 455-472, 2010.

BAUMOL, W. J. "On rational satisficing”. In: In: Augier, M.; March, J. Models of a Man-essays in memory of Herbert A. Simon. MIT Press, Cambridge, Massachusetts e London, England, 2004, p. 57-66, 2004.

CAMERER, C. F.; LOEWENSTEIN, G. "Behavioral economics: past, present, future". In: Camerer, C. F., Loewenstein, G. e Rabin, M. Advances in behavioral economics Princeton University Press, p. 3-51, 2002.

GIGERENZER, G. "On narrow norms and vague heuristics: a reply to Kahneman and Tversky". Psychological Review, v. 103, n. 3, p. 592-596, 1996a.

GIGERENZER, G. "Reasoning the fast and frugal way: models of bounded rationality". Psychological Review, 103 (4), p. 650-669, 1996 b.

KAHNEMAN, D. "Experienced Utility and Objective Happiness". In: Kahneman, D. e Tversky, A. (ed). Choices, Values and Frames, Cambridge University Press, 2000.

KAHNEMAN, D. Maps of bounded rationality: a perspective on intuitive judgment and choice. Prize Lecture. 2002a. Disponível em: http://nobelprize.org/nobel_prizes/economics/laureates/2002/

kahnemann-lecture.pdf. Acesso em: 1/05/2009.

KAHNEMAN, D. Autobiography. 2002b. Disponível em: http://nobelprize.org/nobel_prizes/ economics/ laureates/2002/kahneman-autobio.html. Acesso em: 15 de julho de 2009.

KAHNEMAN, D. "Maps of bounded rationality: psychology for behavioral economics". American Economic Review, 93 (5), p. 1449-1475, 2003.

KAHNEMAN, D.; TVERSKY, A. "Prospect theory: an analysis of decision under risk". Econometrica, 47 (2), p. 263-291, 1979.

KAHNEMAN, D. \& TVERSKY, A. “On the reality of cognitive illusions”. Psychological Review, v. 103, n. 3, p. 582-591, 1996.

KAHNEMAN, D.; TVERSKY, A. “Choices, Values, and Frames”. In: Kahneman, D., Tversky, A (eds) Choices, Values, and Frames. Cambridge University Press, Cambridge, p. 1-16, 2000.

KLAES, M. \& SENT, E-M. A conceptual history of the emergence of bounded rationality. ESHET Conference, p. 1-32. 2003. Disponível em: http://citeseerx.ist.psu.edu/viewdoc/download?

doi=10.1.1.7.7036\&rep= rep1\&type=pdf Acesso em: 12 de julho de 2009.

MARCH, J. G.; SIMON, H. A. Teoria das Organizações. FGV. Rio de Janeiro, 1972[1958].

MURAMATSU, R. "Emotions in Action - an inquiry into the explanation of decision-making in the real economic world". Tese de Doutoramento apresentada a Universidade Erasmus de Rotterdam, 2006. 
RUBINSTEIN, A. "Discussion of 'Behavioral Economics"”. In: BLUNDELL, R.; NEWEY, W. K.; PERSSON, T. (ed.) Advances in Economics and econometrics: theory and applications, Ninth World Congress, v. 2 Cambridge University Press, New York, 2006.

SENT, E-M. "Sargent versus Simon: bounded rationality unbound." Cambridge Journal of Economics, 21 (3), p. 323-338, 1997.

SENT, E-M. "Behavioral Economics: how psychology made its (limited) way back into economics". History of Political Economy, 36 (4), p. 735-760, 2004.

SENT, E-M. “Simplifying Herbert Simon”. History of Political Economy 37 (2), p. 227-232, 2005.

SILVEIRA, A. M. da "Aplicabilidade de teorias: microneoclássica e estratégia empresarial" Revista de Economia Política, v. 14, n. 2 (54), p. 53-76, 1994.

SILVEIRA, A. M. da “A indeterminação de Sênior” Revista de Economia Política, v.11, n. 4 (44), p. 70-88, 1991.

SIMON, H. A. "The Proverbs of Administration". Public Administration Review, 6 (1), p. 53-67, 1946.

SIMON, H. A. Models of Man New York: John Wiley \& Sons, 1957.

SIMON, H. A. "Theories of decision-making in economics and behavioral science". American Economic Review, 49 (3), p. 253-283, 1959.

SIMON, H. A. "Rational Decision Making in Business Organization" American Economic Review, 69 (4), p. 493-513, 1979.

SIMON, H. A. “A racionalidade do processo decisório em empresas” Edições Multiplic, 1 (1), p. 25$58,1980$.

SIMON, H. A. "Human Nature in Politics: the dialogue of psychology with political science" American Economic Review, 79 (2), p. 293-304, 1985.

SIMON, H. A. "Bounded Rationality”, in J. Eatwell et al., eds., The New Palgrave Dictionary of Economics, v. 1 London: MacMillan Press Ltd., p. 266, 1987.

SIMON, H. A. "Invariants of Human Behavior". Annu. Rev. Psychol., 41, p. 1-19, 1990.

SIMON, H. A. "The Human Mind: The Symbolic Level”. The American Philosophical Society, 137 (4), p. 638-647, 1993.

SIMON, H. A. The science of artificial, 3a edição, MIT Press, Cambridge, Massachusetts e London, England, 1996 [1969].

SIMON, H. A.; BONINI, C. P. "The size distribution of business firms". American Economic Review, 48 (8), p. 607-617, 1958.

SIMON, H. A.; SCHAEFFER, J. “The game of chess”. In: Aumann, R. J.; Hart, S. (eds.), Handbook of Game Theory with Economic Applications, ed. Amsterdam: North-Holland, v. 1, p. 1-17, 1989.

TVERSKY, A; KAHNEMAN, D. "Belief in the law of small numbers". Psychological Bulletin, 76 (2), p. 105-110, 1971.

TVERSKY, A; KAHNEMAN, D. "Judgment under uncertainty: heuristics and biases". Science, New Series, 185 (4157), p. 1124-1131, 1974.

TVERSKY, A; KAHNEMAN, D. "Extensional versus intuitive reasoning: the conjunction fallacy in probability judgment”. Psychological Review, 90 (4), p. 293-315, 1983.

TVERSKY, A; KAHNEMAN, D. "Rational Choice and the framing of decisions". Journal of Business, 59 (4), p. S251-S278, 1986.

TVERSKY, A; KAHNEMAN, D. "Rational choice and the framing of decisions". In: Kahneman, D. \& Tversky, A. (ed.) Choices, values and frame. Cambridge University Press, 2000, p. 209-223, 2000. 